\title{
Development of advanced fluoro polymer for nuclear environment
}

\section{原子カ環境用高性能フッ素樹脂の開発}

\author{
Akihiro OSHIMA and Yoneho TABATA \\ Department of Nuclear Engineering, Tokai University, 1117 Kitakaname, Hiratsuka, \\ Kanagawa, 259-12, JAPAN \\ TEL:81-463-58-1211(EX4151) FAX:81-463-50-2017
}

\author{
Shigetoshi IKEDA and Tadao SEGUCHI \\ Japan Atomic Energy Research Institute, Takasaki Radiation Chemistry Research \\ Establishment, 1233 Wataniki-cho, Takasaki, Gunma, 370-12, JAPAN \\ TEL:81-273-46-9442 FAX:81-273-46-9687 \\ ( Received 8, November 1996 Accepted 25, December 1996 )
}

The irradiation temperature effect on polytetrafluoroethylene (PTFE) was investigated by tensile test and thermal analysis. The behavior of mechanical properties and changes of crystallinity on irradiation indicated the network formation in PTFE molecules by radiation induced crosslinking under oxygen-free atmosphere in the molten state around $613 \mathrm{~K}$. The radiation resistance of PTFE was much improved by crosslinking, that is, the irradiation dose at a half value of ultimate elongation was about $1 \mathrm{MGy}$ for $500 \mathrm{kGy}$-crosslinked PTFE, while the dose for non-crosslinked PTFE was only $3.5 \mathrm{kGy}$, so it is expected that the crosslinked PTFE can be applied for the nuclear facilities with relatively high radiation environment. Also, the crosslinked PTFE had light transparency due to the decrease of crystallites, and held the electrical insulation and heat resistance. The abrasion factor in frictional test was greatly improved by crosslinking.

Keywords : PTFE, Radiation, Crosslinking, Mechanical properties, Radiation resistance, Light transmittance, Electrical properties, Frictional properties.

\section{I . INTRODUCTION}

It is well known that polytetrafluoroethylene(PTFE) so-called Teflon ${ }^{\circledR}$ has the excellent properties in electric insulation, high frictional properties, high stability to most chemical solvents and heat resistance in polymer materials. Thus, PTFE is widely used for various purposes under severe conditions. However, PTFE is extremely sensitive to radiation occurring chain scission, to result that the mechanical properties degrade with a small dose of a few kGy either in air or even under vacuum irradiation. ${ }^{1}$ Therefore, PTFE with excellent properties has not been applied in radiation fields such as in nuclear or space environments.

It has been believed past long years that PTFE can't take place crosslinking by any methods as chemical agents and ionizing irradiation. However, in our previous studies on irradiation effects of fluoro-polymers, it was found that PTFE could be induced crosslinking by $\gamma$-rays and electron beams(EB) irradiation under a special condition, where the irradiation was carried out at high temperature of the molten state of PTFE under oxygen-free atmosphere. $^{2-6}$

In this paper, the processing of PTFE crosslinking by ionizing radiation, and the radiation resistance of crosslinked PTFE and other properties are reported, on the point of 
advanced polymer materials for nuclear environment.

\section{II . EXPERIMENTAL}

\section{A. Materials and crosslinking}

PTFE film with $500 \mu \mathrm{m}$ thickness supplied from Asahi Glass Co. Ltd. was used for the experiments. The molecular weight was about 9million, which was determined by Suwa's equation $^{7}$ using a differential scanning calorimetric measurement. PTFE film of $30 \times$ $9 \mathrm{~cm}^{2}$ size was put in an EB irradiation vessel with heating device. ${ }^{8}$ The film was heated up to $613 \mathrm{~K}$ controlled within the range of $\pm 3 \mathrm{~K}$ in argon gas atmosphere, and irradiated up to $10 \mathrm{kGy}$ to $3 \mathrm{MGy}$ with a dose rate of $0.6 \mathrm{kGy} / \mathrm{s}$ by an electron accelerator of $2 \mathrm{MeV}$ installed at Japan Atomic Energy Research Institute (JAERI). The PTFE specimens with different crosslinking density were prepared by changing irradiation dose. Each crosslinked PTFE was cut to a dumb-bell shape(ASTM D-1822L) specimen for the tensile test.

\section{B. Irradiation for radiation resistant test}

The radiation resistance of the crosslinked PTFE was evaluated by the measurements of mechanical and thermal properties after ${ }^{60} \mathrm{Co} \gamma$ -irradiation under vacuum or in air at room temperature(297K). The specimen for vacuum irradiation was sealed in a glass tube after evacuation to $10^{-1} \mathrm{~Pa}$ for about 24 hours, then irradiated up to $2 \mathrm{kGy}-2.1 \mathrm{MGy}$ with a dose rate of $10 \mathrm{kGy} / \mathrm{h}$. Also, the specimens were irradiated in air up to $2 \mathrm{kGy}-600 \mathrm{kGy}$ with the same dose rate.

\section{Measurement}

The mechanical properties measurement was carried out at room temperature using a tensile test machine(INSTRON type 4302). The stress-strain(S-S) curves of the dumb-bell specimens were observed with a cross head speed of $200 \mathrm{~mm} / \mathrm{min}$. The ultimate elongation, tensile strength, yield strength and modulus were determined from the S-S curve.
The melting(Tm) and the crystallization (Tc)temperatures, and the heat of crystallization $(\Delta \mathrm{H})$ were measured by using a differential scanning calorimeter(DSC ; Parkin Elmer, DSC-7) under nitrogen atmosphere. Both the heating and the cooling rates in the DSC measurement were $20 \mathrm{~K} / \mathrm{min}$. The heat of crystallization was determined from the peak area in the DSC thermogram at crystallization. The melting and the crystallization temperature were determined at the respective peak in the thermograms.

The light transmittance was measured using a spectro-photometer(Beckman, DU-65) at room temperature in air in the range from $200 \mathrm{~nm}$ to $900 \mathrm{~nm}$. The spectrum of each specimen was observed with a scanning speed of $500 \mathrm{~nm} / \mathrm{min}$.

The electric properties as loss of the dielectricity $(\tan \delta)$ and dielectric constant $(\varepsilon)$ at $60 \mathrm{~Hz}$ and volume resistance were measured by JIS method at room temperature in air.

Friction coefficient $(\mu)$ and abrasion factor by friction were measured using a Matsubara type friction testing machine at room temperature in air. Testing pressure and velocity were $2.5 \mathrm{~kg} / \mathrm{cm}^{2}$ and $0.5 \mathrm{~m} / \mathrm{sec}$ against the friction material of SUS 304.

\section{RESULT AND DISCUSSION}

\section{A. Radiation induced crosslinking of PTFE}

Figure 1 shows the ultimate elongation (strain at break) and tensile strength(stress at break) against irradiation temperature for PTFE after irradiation to $100 \mathrm{kGy}$ at various temperatures in inert gas atmosphere. For the virgin(non-irradiated PTFE), the ultimate elongation and tensile strength are about $400 \%$ and $55 \mathrm{MPa}$, respectively. Both ultimate elongation and tensile strength decrease with increasing irradiation temperature until around the melting temperature $(600 \mathrm{~K})$ of PTFE, but they change drastically around $600 \mathrm{~K}$, and the sharp peaks in both values are seen at around $613 \mathrm{~K}$. At temperatures higher than around $633 \mathrm{~K}$, both ultimate elongation and tensile strength have small value, and the mass loss was accelerated with dose, especially, at the 


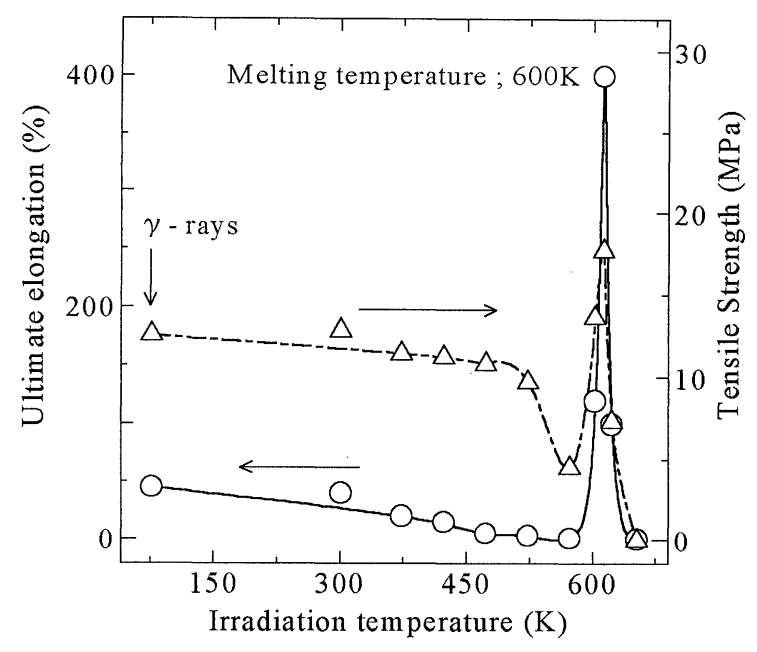

FIG.1. Relationship between mechanical properties and irradiation temperature for PTFE irradiated to $100 \mathrm{kGy}$ in inert gas atmosphere. Irradiation was carried out with $\gamma$-rays at $77 \mathrm{~K}$ in liquid nitrogen, and electron beam at the other temperatures in argon gas; $\bigcirc$ : Ultimate elongation, $\Delta$ : Tensile strength.

surface of films.

The molecular weight of PTFE calculated from Suwa's equation ${ }^{7}$ decreased with increase of irradiation temperature until $600 \mathrm{~K}$. The decrease of molecular weight corresponds to the decay in mechanical properties. The degradation of PTFE by irradiation is due to main chain scission, so the experimental results indicate that the probability of chain scission

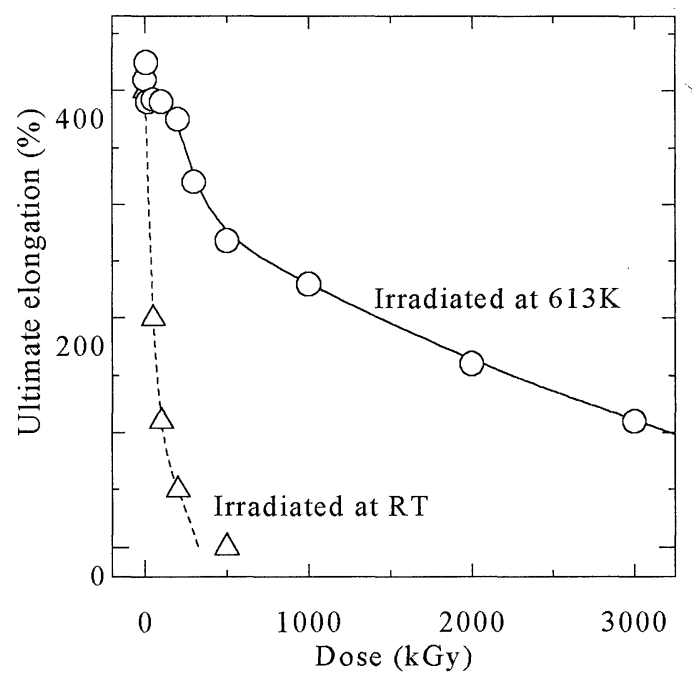

FIG.2. Ultimate elongation as function of EB dose for PTFE irradiated in argon gas at room temperature and $613 \mathrm{~K} ; \bigcirc: 613 \mathrm{~K}, \triangle$ : room temperature. increases with irradiation temperature below the melting point. Above $633 \mathrm{~K}$, the chain scission occurs, and the process may be accompanied by thermal depolymerization. At around $613 \mathrm{~K}$, the radiation induced chemical reactions are changed extremely, where the crosslinking proceeds and the chain scission is much reduced.

On the basis of the above experiments, the dose dependency at $613 \mathrm{~K}$ was investigated. The ultimate elongation against dose is shown in Fig. 2 for irradiated PTFE up to $3 \mathrm{MGy}$ in argon gas atmosphere at room temperature and $613 \mathrm{~K}$. The ultimate elongation decreased sharply with dose at room temperature irradiation, which was the same as a previous paper. ${ }^{9}$ However, for the irradiation at $613 \mathrm{~K}$ the ultimate elongation remains over $150 \%$ after 2MGy irradiation.

Figure 3 shows the yield strength, which was the stress at the knee point of S-S curve at the strain of about $10 \%$, against dose for irradiated PTFE up to $3 \mathrm{MGy}$ in argon gas atmosphere at room temperature and $613 \mathrm{~K}$. The yield strength for PTFE irradiated at 613K increases with dose. The modulus, which is determined from the slope of the initial line in the S-S curve increased also with dose. Both increase in the yield strength and in the modulus indicate the increase of network

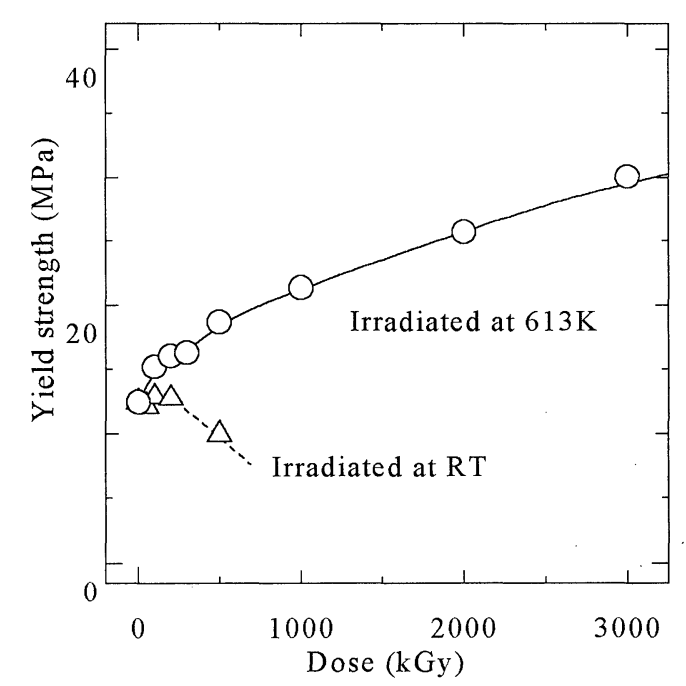

FIG.3. Yield strength as function of EB dose for PTFE irradiated in argon gas at room temperature and $613 \mathrm{~K} ; \bigcirc: 613 \mathrm{~K}, \triangle$ : room temperature. 
density in PTFE molecules by crosslinking. Generally, it is accepted that these values increase with increasing crosslinking density for linear polymers. Therefore, these results indicate that the crosslinking takes place preferentially in the molten state and a network structure is formed by radiation induced crosslinking.

The melting(Tm) and the crystallization (Tc) temperatures, and heat of crystallization $(\triangle \mathrm{H})$ of PTFE by radiation induced crosslinking was measured by thermal analysis using a DSC. Both Tm and Tc hardly changed by irradiation except the crosslinking condition(613K, oxygen-free atmosphere), but, Tm and Tc shift to lower temperatures by progress of the crosslinking density. Figure 4 shows the $\Delta \mathrm{H}$ against dose for irradiated PTFE at room temperature and $613 \mathrm{~K}$ in argon gas atmosphere. The $\Delta H$ reflects the amount of the crystalline component in PTFE. PTFE irradiated at room

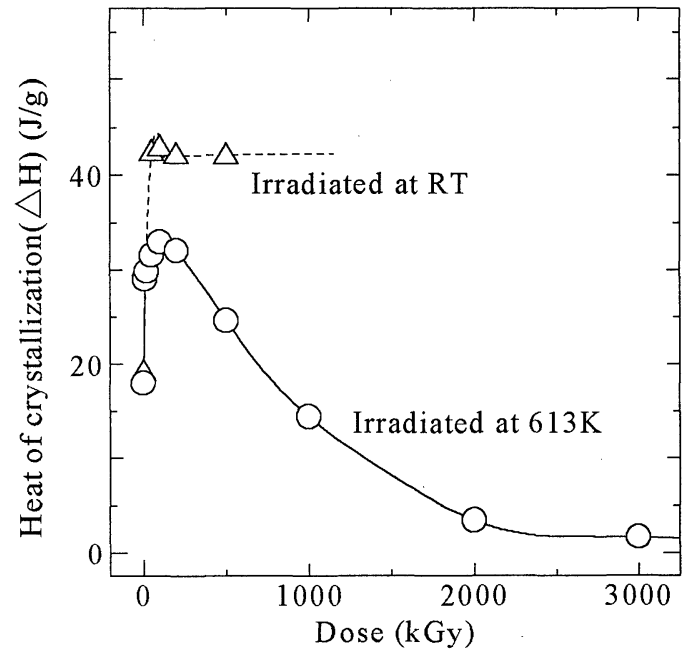

FIG.4. Heat of crystallization $(\Delta \mathrm{H})$ as function of $\mathrm{EB}$ dose for PTFE irradiated in argon gas at room temperature and $613 \mathrm{~K} ; \bigcirc: 613 \mathrm{~K}, \triangle$ : room temperature. temperature has high crystallinity due to the crystallization of amorphous region through the main chain scission as reported in previous works. $^{10,11}$ On the other hand, for the molten state irradiation at $613 \mathrm{~K}$, the crystallinity decrease greatly with dose except at a small dose. It means that the crystallization is much depressed by the radiation crosslinking at the molten state. As the crystalline region decreased with the progress of crosslinking density, the PTFE films became transparent and had a rubber like property. For the irradiated above $633 \mathrm{~K}$, the crystallinity decreased with dose though the mechanical properties degraded where radiation crosslinking proceeds and thermal decomposition would be accompanied.

The changes of mechanical and thermal properties of PTFE with various crosslinking are summarized in Table 1.

\section{B. Radiation resistance of crosslinked PTFE}

For the virgin PTFE, both of the ultimate elongation and tensile strength degrade greatly with a few kGy by $\gamma$-rays irradiation at room temperature under vacuum and in air, which has been the same as a previous paper. ${ }^{9}$ Ultimate elongation for three different radiation crosslinked PTFE(RX-PTFE) are shown in Figs.5-(a) and (b), as a function of $\gamma$-irradiation dose at room temperature under vacuum and in air, respectively. The ultimate elongation and the tensile strength for RX-PTFE degraded gradually with dose. For examples, the doses at a half value of the ultimate elongation after irradiation under vacuum are $1.1 \mathrm{MGy}$ for RX-

TABLE 1. Mechanical and thermal properties of crosslinked PTFE(RX-PTFE).

\begin{tabular}{|c|c|c|c|c|c|c|}
\hline \multirow{2}{*}{$\begin{array}{l}\text { Sample } \\
\text { code }\end{array}$} & \multirow{2}{*}{$\begin{array}{c}\text { Dose for EB } \\
\text { crosslink (kGy) }\end{array}$} & \multicolumn{3}{|c|}{ Mechanical properties } & \multicolumn{2}{|c|}{ Thermal properties } \\
\hline & & $\mathrm{Eb}^{*} 1_{(\%)}$ & $\mathrm{Ts}^{* 2}(\mathrm{MPa})$ & $\mathrm{Ys}^{* 3}(\mathrm{MPa})$ & $\operatorname{Tm}^{*} 4\left({ }^{\circ} \mathrm{C}\right)$ & $\Delta \mathrm{H}^{* 5}(\mathrm{~J} / \mathrm{g})$ \\
\hline Virgin & $\overline{0}$ & $\overline{402}$ & $\overline{55.0}$ & 11.3 & 328 & 20 \\
\hline $\mathrm{RX}-50$ & 50 & 395 & 21.4 & 13.0 & 323 & 29 \\
\hline RX-100 & 100 & 380 & 22.9 & 15.2 & 318 & 33 \\
\hline RX-500 & 500 & 271 & 25.6 & 18.7 & 298 & 25 \\
\hline$R X-1 M$ & 1000 & 235 & 26.0 & 21.4 & 281 & 16 \\
\hline $\mathrm{RX}-3 \mathrm{M}$ & 3000 & 100 & 32.5 & 30.1 & 178 & 1.7 \\
\hline
\end{tabular}



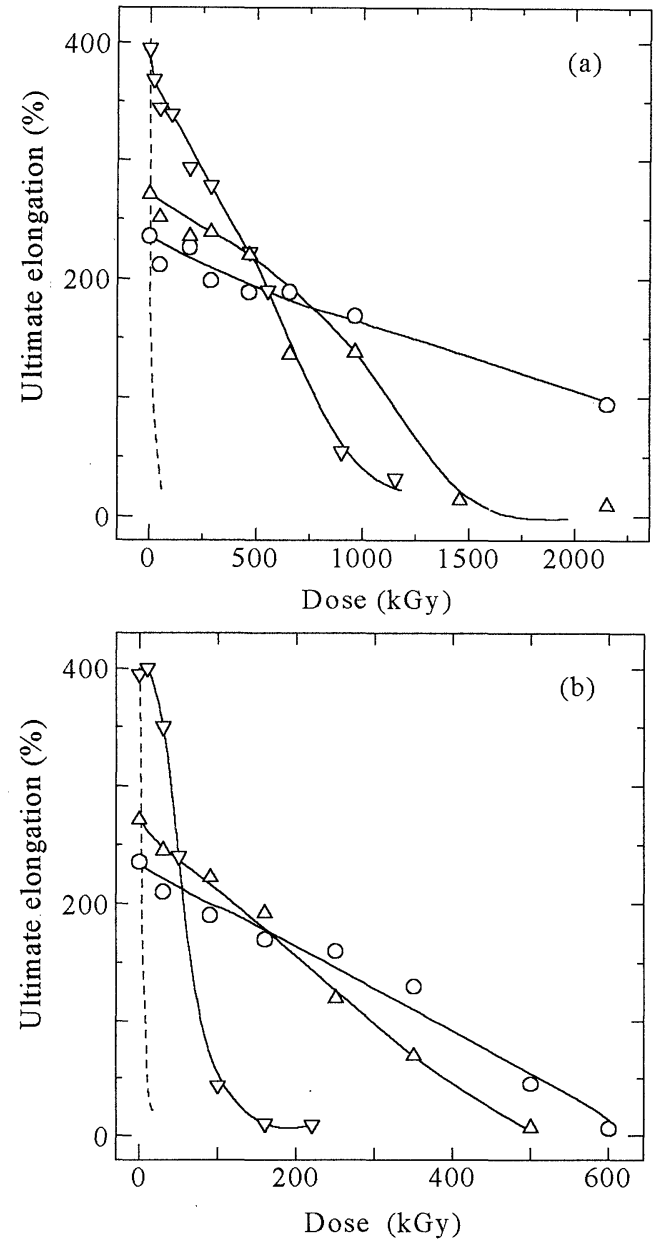

FIG.5. Ultimate elongation at break as function of $\gamma$-dose for crosslinked PTFE; $\gamma$ irradiation was carried out at room temperature under vacuum(a) and in air(b). $\bigcirc$ : 1MGycrosslinked, $\triangle:$ 500kGy-crosslinked, $\nabla: 50 \mathrm{kGy}-$ crosslinked, ---- (Broken line) : virgin(non-crosslinked).

500 , and 1.9MGy for RX-1M, and in a case of irradiation in air, the doses are 250kGy and $360 \mathrm{kGy}$, respectively. In contrary, for virgin PTFE, the dose at a half elongation value was only $3.5 \mathrm{kGy}$ under vacuum and $2 \mathrm{kGy}$ in air. In a case of $\mathrm{RX}-1 \mathrm{M}$, the radiation resistance, dose at a half of ultimate elongation under vacuum at room temperature, was 540 times higher than the virgin. Doses at the half values for RXPTFE were compiled in Table 2, as an index of radiation resistance for $\gamma$-rays irradiation at room temperature under vacuum and in air. The radiation resistance increases greatly with the increase of crosslinking density either in air or even under vacuum. The radiation resistance under vacuum irradiation is higher by several times than that in atmospheric irradiation as same as other polymer materials. ${ }^{12}$

The heat of crystallization $(\Delta \mathrm{H})$ of virgin and RX-PTFE after $\gamma$-rays irradiation at room temperature under vacuum and in air, increases sharply with a small dose for virgin as same work as other researchers, ${ }^{10,11}$ but it is suppressed by increasing in crosslinking density. The changes of $\Delta \mathrm{H}$ are well related to the mechanical properties in Fig. 5, that is, the crystallinity increase reduces the mechanical properties.

For PTFE, the molecules are aligned in extended chain to form crystals with band structure, and the crystal size(band thickness) is about $0.2-0.5 \mu \mathrm{m}^{13,14}$ which is quite different from other polymers such as polyethylene or polypropylene. For the virgin, effective chain scission occurs in disordered, boundary region in the polymer matrices, which makes to proceed further crystallization much easier. As the result, a large number of small crystallites could be formed. The deterioration of noncrosslinked PTFE in mechanical properties would be explained with above model.

As the crosslinking increases, the crystallization temperature decreases. This is indicating that size of the crystallites becomes small, and crystallites with small size are dispersed in the crosslinked polymer matrices. The crosslinked PTFE shows the low crystallinity, because the crosslinking disturbs the alignment of molecular chains as same as other polymers. For the PTFE with a certain crosslinking density, the crystallization of chains could be suppressed to some extent by the network structure. The network structure of RX-PTFE has a high yield strength and a moderate ultimate elongation. The big improvement of the radiation resistance in mechanical properties for crosslinked PTFE can be explained above mechanisms.

TABLE 2. Index of radiation resistance of crosslinked PTFE ; Dose at half value in ultimate elongation(Eb) and tensile strength(Ts).

\begin{tabular}{lccccc}
\hline Sample & \multicolumn{2}{c}{ Dose at $1 / 2 \mathrm{~Eb}(\mathrm{kGy})$} & & \multicolumn{2}{c}{ Dose at $1 / 2 \mathrm{Ts}(\mathrm{kGy})$} \\
\cline { 2 - 3 } \cline { 5 - 6 } code & vacuum & air & & vacuum & air \\
\hline Virgin & 3.5 & 2.0 & & 3.5 & 1.5 \\
RX-50 & 510 & 70 & & $>900$ & 100 \\
RX-500 & 1050 & 250 & & $>2100$ & 450 \\
RX-1M & 1900 & 360 & & $>2100$ & $>600$ \\
\hline
\end{tabular}


Concerning the improvement of radiation resistance, energy or charge transfer to the crosslinking sites also may play an important role. $^{15}$

The radiation degradation of crosslinked PTFE is more accelerated in air than under vacuum, as same as that for other chain scission type polymers. In air irradiation, the oxidation takes place to accelerate the chain scission, and the mechanism of radiation induced oxidation for PTFE was studied by electron spin resonance(ESR) technique. ${ }^{16}$ Generally, radiation induced oxidation in polymer sheet depends on the dose rate and the sheet thickness due to the oxygen diffusion control into the sheet. For PTFE, the oxygen permeability is rather large, the oxidation proceeds well throughout the PTFE film of $500 \mu \mathrm{m}$ thickness when the $\gamma$-rays dose rate is high as $10 \mathrm{kGy} / \mathrm{h}$ or so.

The radiation resistance increases greatly with the crosslinking density both under vacuum and in air, so it is expected that the crosslinked PTFE can be used for the nuclear facilities with relatively high radiation environment. The improvement by crosslinking is very much pronounced compared with other polymers, which indicates that the change of morphology in PTFE by crosslinking would much contribute to radiation resistance.

\section{Other properties of crosslinked PTFE}

Light transmission for various crosslinked PTFE films $(500 \mu \mathrm{m})$ as a function of the wavelength was measured as shown in Fig.6. The virgin PTFE was a very poor transparency at wide range from near infrared to near ultra violet. However, the transmission increases much in the infrared range with progress of the crosslinking density. For near ultra violet range of $320 \mathrm{~nm}$, the $90 \%$ transmission can be achieved after $3 \mathrm{MGy}$ irradiation in crosslinking condition(RX-3M). The light transmission would be disturbed by light scattering of PTFE crystals. With increase of crosslinking density, the size of crystallites become small and the quantity decreases, so the light transmission was improved by decreasing the light scattering

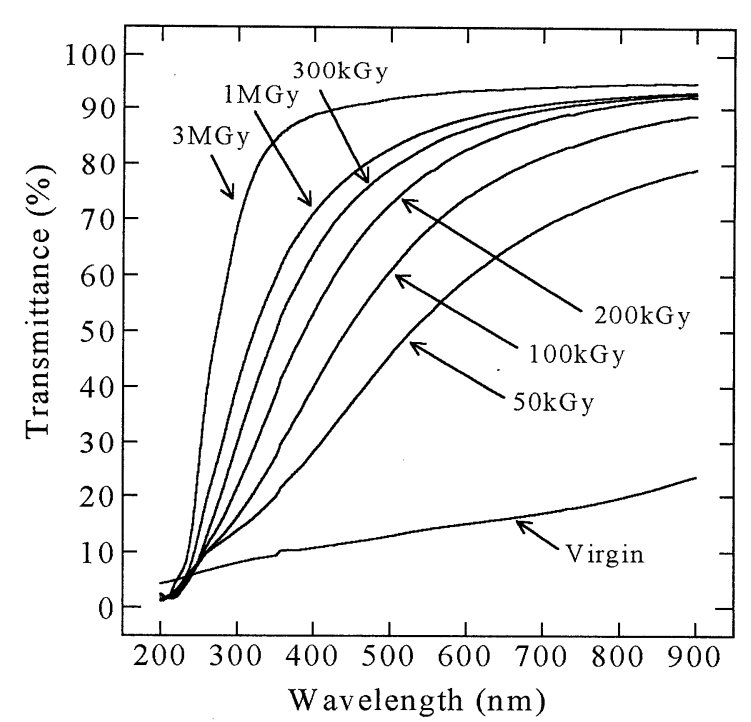

FIG.6. Light transmittance as function of weavelength for crosslinked PTFE.

with the crosslinking.

The change of electric properties by crosslinking was listed in Table 3 . The loss of dielectricity $(\tan \delta)$ increased slightly and dielectric constant $(\varepsilon)$ tended to decrease by the progress of crosslinking density. The volume resistance was hardly changed by highly crosslinking PTFE as RX-1M. Thus, it is confirmed that the electrical insulation are held for crosslinked PTFE.

Friction coefficient $(\mu)$ and abrasion factor for virgin and crosslinked PTFE were listed in Table 4. The $\mu$ of virgin is very low and decreased at small crosslinking density but

TABLE 3. Electrical properties of crosslinked PTFE ; Volume resistance(V.R.), loss of the dielectricity(tan $\delta$ ) and dielectric constant $(\varepsilon)$ at $60 \mathrm{~Hz}$.

\begin{tabular}{cccc}
\hline \multirow{2}{*}{$\begin{array}{c}\text { ample } \\
\text { code }\end{array}$} & \multicolumn{4}{c}{ Electrical properties } \\
\cline { 2 - 4 } V.R. $(\Omega \mathrm{cm})$ & $\tan \delta(\%, 60 \mathrm{~Hz})$ & $\varepsilon(60 \mathrm{~Hz})$ \\
\hline Virgin & $>1.0 \times 10^{18}$ & 0.004 & 2.05 \\
RX-100 & $>1.0 \times 10^{18}$ & 0.004 & 1.98 \\
RX-500 & $>1.0 \times 10^{18}$ & 0.005 & 1.97 \\
RX-1M & $>1.0 \times 10^{18}$ & 0.005 & 1.90 \\
\hline
\end{tabular}

TABLE 4. Frictional properties of crosslinked PTFE ; Friction coefficient $(\mu)$ and abrasion factor(A).

\begin{tabular}{ccc}
\hline Sample & \multicolumn{2}{c}{ Frictional properties } \\
\cline { 2 - 3 } code & $\mu$ & $\mathrm{A}\left(\mathrm{cm}^{2} \cdot \mathrm{s} / \mathrm{kgf} \cdot \mathrm{m} \cdot \mathrm{h}\right)$ \\
\hline Virgin & 0.35 & $2.0 \times 10^{-2}$ \\
RX-100 & 0.31 & $4.6 \times 10^{-6}$ \\
RX-500 & 0.41 & $1.9 \times 10^{-5}$ \\
RX-1M & 0.44 & $2.8 \times 10^{-5}$ \\
\hline
\end{tabular}


tends to increase. The abrasion factor decreases drastically by crosslinking, that is, the value decreases by more than 3 order after $100 \mathrm{kGy}$ crosslinking(RX-100).

\section{GONCLUSION}

Main chain scission of PTFE is the predominant reaction on irradiation and tends to increase with irradiation temperature below the melting temperature. On the other hand, the crosslinking proceeds well by irradiation in the molten state at around $613 \mathrm{~K}$ in the oxygen-free atmosphere. At higher temperature than $633 \mathrm{~K}$, the depolymerization proceeds because of the combined effects of thermal stress and radiation.

The crosslinked PTFE showed an excellent radiation resistance, which is the same grade of polyethylene or polyvinylchrolide(PVC), so it is expected to apply for the nuclear environment such as nuclear facilities. Also, the crosslinked PTFE became transparency due to the decrease of crystallites. The radiation resistance and abrasion factor of PTFE were greatly improved by crosslinking. The crosslinked PTFE holds electrical insulation and heat resistance like as virgin.

\section{ACKNOWLEDGEMNTS}

The authors acknowledge continuing encouragement by Prof. K. Kawashima of Tokai University. The authors acknowledge the staffs of EB and $\gamma$-rays irradiation service of JAERI Takasaki, and the senior manager $M$. Morozumi of Asahi Glass Co. Ltd. and general manager $\mathrm{H}$. Yagyu of Hitachi Cable Ltd. for measurements of the crosslinked PTFE.

\section{REFERENCES}

${ }^{1} \mathrm{M}$. Dole, in The radiation chemistry of Macromolecules II edited by M. Dole, Chap.9, pp.167-178, Academic Press
(1973).

${ }^{2}$ Y. Tabata, in Proceedings of Solid State Reactions in Radiation Chemistry, Taniguchi Conf. Sapporo, Japan, 1992, pp.118-120.

${ }^{3}$ A. Oshima, Y. Tabata and T. Seguchi, in Proceedings of $14^{\text {th }}$ International Symposium on Fluorine Chemistry, Yokohama, Japan, 1994.

${ }^{4}$ A. Oshima, Y. Tabata, S. Ikeda, K. Otsuhata, H. Kudoh and T. Seguchi, in Proceedings in The $6^{\text {th }}$ Japan-China Bilateral Symposium on Radiation Chemistry, Tokyo, Japan, 1994.: JAERI-Conf. 95-003, pp.487-491.

5 A. Oshima, Y. Tabata, H. Kudoh and T. Seguchi, Radiat. Phys. Chem., 45, 269 (1995).

6 A. Oshima, S. Ikeda, T. Seguchi and Y. Tabata, Radiat. Phys. Chem., in press (1996).

7 T. Suwa, M. Takehisa and S. Machi, J.Appl.Polym.Sci., 17, 3253 (1973).

8 Y. Haruyama, A. Oshima, S. Ikeda, H. Sunaga, H. Takizawa and T. Seguchi, Report of Japan Atomic Energy Research Institute, JAERI-Tech 95-003 (1995).

9 H. Kudoh, N. Kasai, T. Sasuga and T. Seguchi, Radiat. Phys. Chem., 43, 329 (1994).

${ }^{10}$ D. E. Kline and J. A. Sauer, J. Polymer Sci., A1, 1621 (1963).

${ }^{11}$ M. Tutiya and K. Yamamoto, Oyo Buturi, 34, 424 (1965).

12 T. Seguchi, Kogyo Zairyo 32, 71 (1984).

${ }^{13}$ C. W. Bunn, A. J. Cobbold and R. P. Palmer, J. Polymer. Sci., 28, 265 (1958)

14 Tadao Seguchi, Report of Japan Atomic Energy Research Institute, JAERI-M 7394, 151 (1977).

${ }^{15}$ Y. Tabata, A. Oshima, K. Takashika and T. Seguchi, Radiat. Phys. Chem., in press (1996).

16 M. Iwasaki, Fluorine Chem. Rev. 5, 1 (1971).

'96 SAS Intelligent Symposium 